\title{
The Design of Public Computer Lab Management System Based on Network Environment
}

\author{
Fayou Wang \\ Department of Property and Equipment Management, Linyi University, Linyi, China \\ wangfayou@lyu.edu.cn
}

Keywords: Equipment management; Public computer lab; Information system; Multi-strategic; Network environment

\begin{abstract}
Along with the computer has become increasingly widespread, the public computer lab undertake more and more tasks. Some problems in traditional computer lab management become highlighted. This paper proposes a public computer lab management system consists four functional parts. The proposed system provides a convenient and efficient way for the teachers and students to communicate and improves the management level of public computer lab. This system is of great significance for the new situation of laboratory management.
\end{abstract}

\section{Introduction}

With the development of computer technology, more and more industries have been using computers for research and production. Now most of the domestic computer experiment teaching is not only established for the computer science students for professional education, but also carried out basic computer education to other majors. Obviously, different professions students need to learn and use a variety of software. The content of public computer lab management includes a computer lab environment and safety, behavior and rules of the users, network maintenance, update of software and hardware and the use of multimedia software. Though there's a large number of computers in the lab, the vast majority of students are of different majors, which make the management of a public computer lab extremely hard. As mentioned above, it is of great significant to design a public computer lab management system for science and effective management.

The rest of this paper is organized as follows. The second part of this paper analysis the requirement and design rules of the target public computer laboratory management system. In the third section, the design principles and basic ideas are presented. Then the detailed design method and steps are proposed in the next section. At the last section, the whole system is comprehensively analyzed and summarized.

\section{Requirement Analysis}

As mentioned before, the establishment of school public computer laboratory is used not only to ensure the basic computer experiment class, but also to meet the requirements of students in various majors. School is a special society of fixed schedule where classes of different majors and subjects are working almost at the same time. Though there is a large majority of computer laboratory in schools, they cannot afford the hardware and software platform requires. What's more, a simple laboratory increase will result in laboratory management confusion, the arrangement and management of the public computer laboratory is more complex. So the scientific and effective management of public computer laboratory, which can ensure the operation and the high efficiency is of great importance.

Along with the construction of a digital campus, campus network has covered the whole region, which can realize the information interchange in school. Campus card system is a commonly used personal identity way based on the campus network. It provides relatively perfect service functions such as identification, consumption, student management and financial transactions. This provides a solid material foundation to overcome the disadvantages in the management of computer laboratory. 
The existing campus network infrastructure should be made full use to design a set of appropriate laboratory management system. The target system should have functions of project management, teaching management, equipment management, data query and data statistics. This will provide great help for public laboratory management and help to make experimental teaching work smoothly.

\section{Design Principles}

The design of a public computer laboratory management system should take actual environment, hardware and software situations, staff status and service object into account. The proposed system uses a mixing mode of $\mathrm{C} / \mathrm{S}$ and $\mathrm{B} / \mathrm{S}$ where coexist both Intranet and Internet.

The proposed system can be divided into three layers: the bottom layer (business operation layer), middle layer (information management layer) and the top layer (decision support layer). The business layer is the management layer of the network in a laboratory center, using $\mathrm{C} / \mathrm{S}$ structure to responsible for the day-to-day management of experimental teaching laboratory. The information layer is a database management layer and responsible for statistical analysis, including analysis pooled data from business operation layer, generate system status information, report errors and provide decision support for managers. The information management layer is the link and key part of the entire system. The decision support layer is presented as website of the laboratory. It is the information center of internal and facilitates the decision maker information query, data analysis, error recognize and tasks assignment. To the external environment, the information management layer is the sharing channel and platform for information exchange. Database access technology, Web dynamic web technology and information security strategy is the key to realize the system design. Combined with the actual situation of experimental center, the target system is developed under Windows Server 2003 with database MS SQL Server 2000, Microsoft.NET structure. Database manipulation and dynamic query are implemented using ASP.NET and ADO.NET, while the dynamic interaction of the client's function is realized by hypertext markup languages such as HTML, JavaScript and C\#. The basic diagram of the proposed public computer laboratory management system is shown in Fig. 1.

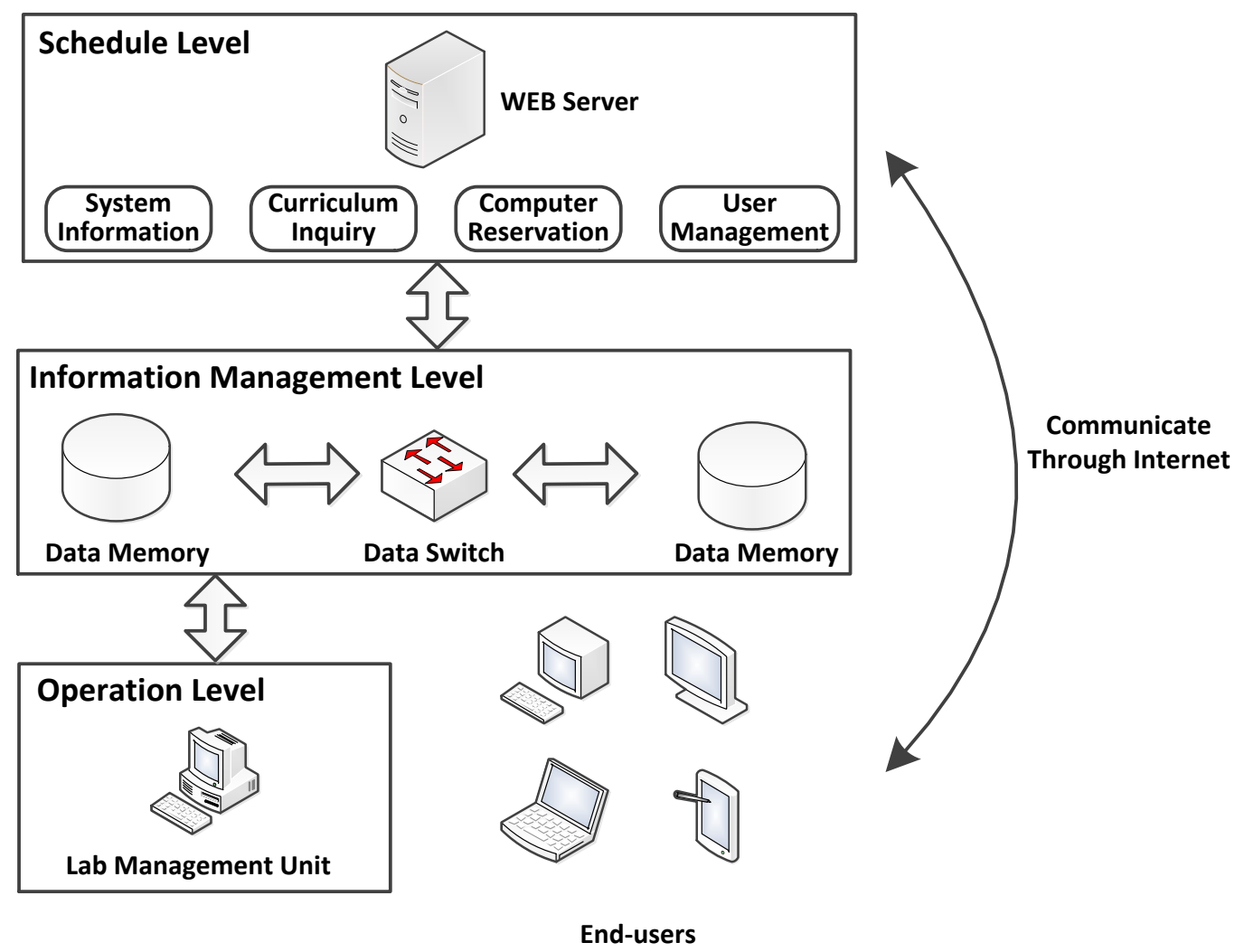

Figure 1. Basic diagram of the proposed public computer laboratory management system 


\section{Functional Design}

Technical Requirements. The management system should follow certain software development system, and the various functions of the system should be closely integrated together to build a complete system. For standardization, the management system should follow certain development standards. In order to facilitate the expansion and other system's access to the system should follow open standards in the resource structure, properties, and database design. For cross-platform convenience, distributed deployment of the management system should be able to run on a variety of platforms. For flexibility, the system should be able to publish different levels of resources based on user permission. In addition, security must be taken in count. The information resources, which includes not only the resource itself, but also the information of the author, providers, reviewers and user associated with the resources, should be observed and managed during the entire life cycle from their generation, storage, use to discontinue use with secure conception.

Implement Steps. The implementation steps can be divided into four stages. The first stage is positioned and planning of the system. The second stage is to select the hardware, detail technology, database design method, division arrangements and implementation progress, which determine the types of data and the use of standardized criteria for the modeling and design of the database. The third stage is to design each module according to the division of overall system architecture and function, complete design work of the system website, and complete the assembly and integration of various functional modules. The last stage is to find system design errors, evaluate software usability and do stress tests to the running ability and load capacity.

Module Functions. The proposed public computer laboratory management system consists of four modules: equipment management subsystem, reservation subsystem, database management subsystem and laboratory website server subsystem. Fig. 2 is the basic composition and mutual relations of the proposed system.

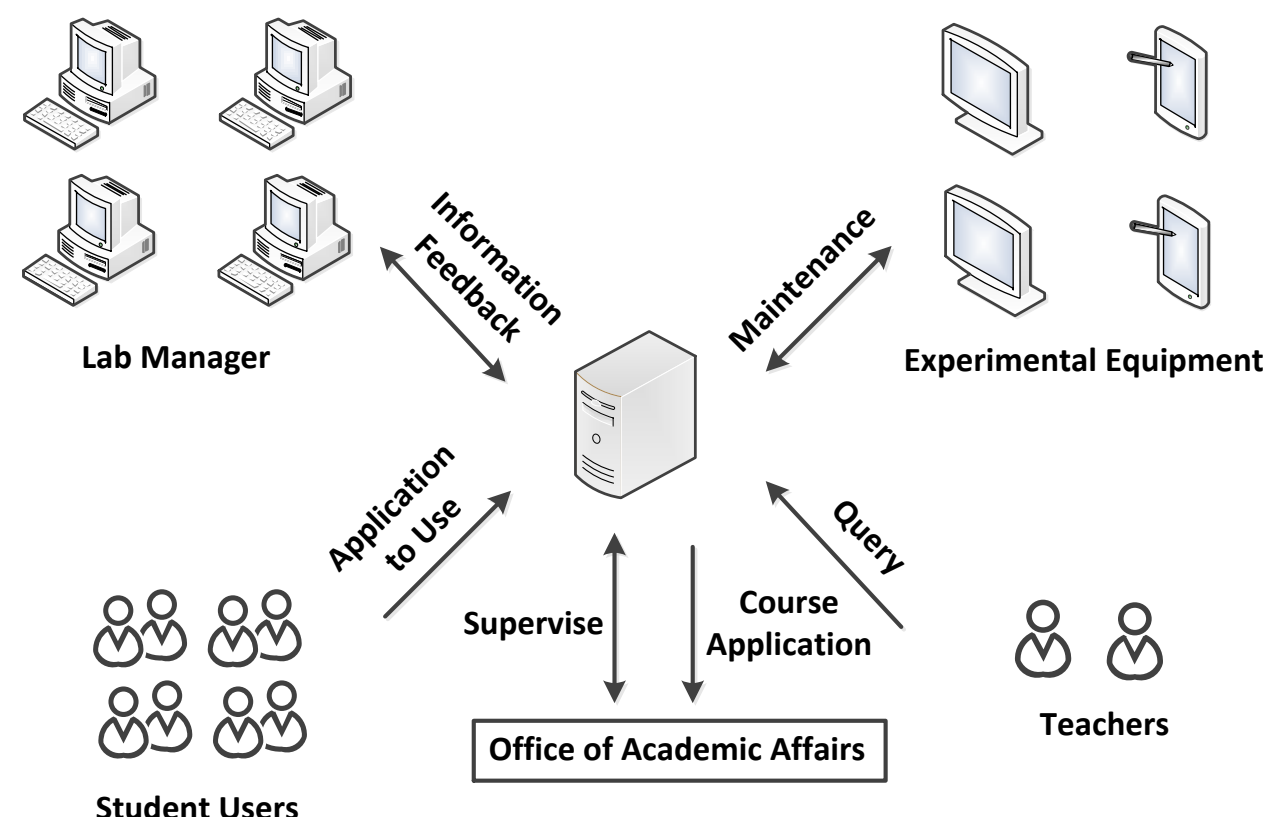

Figure 2. Basic composition and mutual relations of the proposed system

Equipment Management Subsystem records management to undertake the task of teaching, the laboratory maintenance management work and problems handling records. The system function of equipment registration management is used to add, delete and modify the records of the laboratory equipment corresponding to equipment additions, scrap and update. The hardware control function refers to the only legitimates users, such as an appointment user, to open or access experimental equipment to undertake corresponding experiment. Equipment management subsystem use real name 
system for any users, and number each computer and equipment to achieve point to point query and access. According to the accurate usage information, this subsystem can arrange reasonable maintenance time efficiently and effectively.

Reservation subsystem allows students to experiment by booking online registration. Because of the great student demand on experience practice, students may encounter a lot of room arrangement problems outside school hours. The students don't know when the laboratory open in their spare time makes this matter worse. Online Booking experiment provides a reliable basis for the proper laboratory arrangement outside school hours.

Database management subsystem is the center of the public computer laboratory management system. It bears the comprehensive information management of the database of the proposed central laboratory management system, such as laboratory equipment information statistics, personnel information storage, experimental content and log file editing and management, report generation and data backup.

According to the educational course scheduling, the laboratory website server subsystem may generate a semester timetable for the objective laboratory. Students, teachers and computer laboratory administrators can login this system in any place connected to the campus network to access class information. Teachers can replace class time taking free laboratory arrangement information displayed in the subsystem into account. Once the classroom or the class arrangement is changed, the students can receive mails to get the new classroom place and the new class time. In this way, teachers and students can have an online exchange platform. Communicate on such system, one can learn to discuss, and on the other hand, this may provide a way to share notices.

The Latter Extended Service. In terms of public laboratory management mode, we want to realize unattended and automatic attendance of students in the experimental class. So it needs an automatic card reading and recording system based on the network database environment. The system is combined with the campus one-card service. The student books experimental time and experimental instrument through the open laboratory booking system. Then the student's reservation information is stored in the server database. He can be admitted to the laboratory by swiping campus one-card on the booked time. The student is allowed to enter the lab only at the booked time. And if he does not book in advance, he can't enter the lab. After swiping the card, the student's information which recorded in the server database will be retrieved. Then the system opens the power of the booked experimental equipment automatically. And the system records the basic usage information.

\section{Conclusion}

In conclusion, from the perspective of the whole school, the public laboratory management system can be combined with other management systems by campus network. All of the systems from a complete campus card system. The laboratory management system improves the level of laboratory management and the utilization of laboratory resources. What's more, it serves teachers and students more conveniently and efficiently. Implementing collaborative management will be breaking new ground to the university laboratory management software. Meanwhile, it plays an important role to improve the level of teaching and scientific research in colleges.

\section{References}

[1] Yadav A., Gretter S., Hambrusch S., Challenges of a Computer Science Classroom: Initial Perspectives From Teachers, WiPSCE 2015, Nov 9-11(2015), pp. 136-137.

[2] McLoone S., Villing R., O'keeffe S., Using Mobile Touch Devices to Provide Flexible Classroom Assessment Techniques, International Journal of Mobile Human Computer Interaction, Vol. 7, Issue 4(2015), pp. 1-15.

[3] Hu Y., University Public Teaching Information Service Platform Design and Implementation Based on Private Cloud, JDCTA, Vol. 7, Issue 21 (2013), pp. 510-517. 
[4] Mateos V., Bellido L., Vollagra V.A., Access Control for Shared Remote Laboratories, Journal of Research and Practice in Information Technology, Vol. 44, Issue 2 (2012), pp. 111.

[5] Zhu W. Luo C., Multimedia Cloud Computing, Signal Processing Magazine, Vol. 28, Issue 3 (2011), pp. 59-69.

[6] Lee, Greg C., Pei-Lun L., Data structures in flipped classroom: Students' effort and preference, LaTiCE2015, Apr. 9-12 (2015), pp. 152-155.

[7] Nussbaum M., Alcoholado C., Buchi T., A Comparative Analysis of Interactive Arithmetic Learning in the Classroom and Computer Lab, Computer in Human Behavior, Vol. 43(2015), pp. 183-188.

[8] Varma R., Lafever M., Importance of Gender Homophily in the Computer Science Classroom, IEEE Tech. and Soc. Magazine, Vol. 26, Issue 2m pp. 43-47.

[9] Chuang-Kai C., Judy C. R. T., An Intelligent Classroom Management System Based on Wireless Sensor Networks, UMEDIA 2015, Aug. 24-26(2015), pp. 44-48.

[10] Wu-Yuin H., Jian-jie D., Strategies of Promoting Sequential Knowledge Learning in Computer Classroom: Using Pause Class and Instant Peer Scaffold in Attention Zone, ICIET 2010, Sep. 17-19 (2010), pp. 3224-3228.

[11] Nedim M., Computer Classroom Management and Virtualization and Visualization in Education, MIPRO 2009, May 25-29 (2009), pp. 122-127. 